Original Research

\title{
At-Site Flood Frequency Analysis of Annual Maximum Stream Flows in Pakistan Using Robust Estimation Methods
}

\author{
Ishfaq Ahmad ${ }^{1 *}$, Muhammad Fawad', Iram Mahmood ${ }^{2}$ \\ 'Department of Mathematics and Statistics, International Islamic University Islamabad, Pakistan \\ ${ }^{2}$ School of Chemical and Materials Engineering, NUST, Islamabad, Pakistan \\ Received: July 30, 2015 \\ Accepted: September 29, 2015
}

\begin{abstract}
Our paper compares the L-moments (MLM), TL-moments (MTLM), and maximum likelihood estimation (MLE) methods in order to select the best-fit distribution of annual maximum stream flow (AMSF) data for at-site flood frequency analysis (FFA) in Pakistan. Initially this study considered different probability distributions. Best distribution for each site is identified using different goodness of fit tests such as mean absolute deviation index (MADI), Anderson darling (AD) test, probability plot correlation coefficient (PPCC), and L-moments ratio diagram. Results show that GPA distribution is the most suitable distribution for most of the sites, followed by GLO and GEV distributions, respectively. MLM is found to be the most suitable estimation method in finding the best-fit distribution for most of the sites in this study, followed by MTLM and MLE. For at-site FFA we also estimated different return periods associated with given flood magnitudes (quantiles of best fit distribution/maximum annual discharge values). It is found that estimated flows based on fitted distribution are in close agreement with observed flows.
\end{abstract}

Keywords: estimation, L-moments, mean absolute deviation index, return period, TL-moments

\section{Introduction}

Floods, droughts, and heavy storms are some of the manifestations of environmental events that cause tremendous destruction and bring misery to human existence. Flooding can bring havoc to property, infrastructure, animals, plants, and human lives. Floods have been a major challenge in Pakistan for many years. The main reason for these floods is extreme monsoon rainfall due to the unusual climate-change-led seasonal cycle of land temperature in Pakistan that has made the monsoon rainfall more severe and produced a large volume of water in the northern mountainous region of the country. Summer monsoon in the subcontinent is going to be extreme. Temperature, $\mathrm{CO}_{2}$,

*e-mail: ishfaq.ahmad@iiu.edu.pk and $\mathrm{CH}_{4}$ records of past decades represent this change [1]. The monsoon in Pakistan starts in early July and remains until the end of September. Besides human loss, the financial loss in the last six decades is estimated at $\$ 37.554$ billion US.

In construction of flood protection projects, information on flood magnitude and their frequencies is critical [2]. Frequency analysis is the estimation of how often a specified event will happen. The main objective of FFA is to relate the magnitude of extreme events to their frequency of happening through the use of probability distributions [3].

This study is interesting in two aspects, first by selecting a robust estimation method and second by selecting a best distribution for at-site FFA using AMSF data in the country using different goodness fit tests. The first aspect is a prerequisite for the second, in the sense that we need esti- 
mates of the parameters for different candidate distributions in different goodness-of-fit tests to select best-fit distribution. We prefer the estimation method that gives optimum results for these goodness-of-fit tests. As most of the problems in nature follow the Gaussian model and it is very easy to deal with them. But in the case of extreme events our Gaussian model is not the appropriate choice. We cannot ignore these extreme events in our data because they give us some hints for abrupt changes in the phenomena. In such circumstances our usual models and methods of estimation such as maximum likelihood, method of moments, and least square are not appropriate choices. They are all influenced by extreme events. We have alternative methods of estimation of parameters named method of L-moments (MLM) [4] and method of trimmed L-moments (MTLM) [5], which are less affected by such extreme observations without removing them from the data set. The estimates from these methods are more reliable as compared to conventional methods.

MLM is a recently developed estimation methodology in statistics and probability theory commonly used in FFA [2]. MLM introduced by Hosking [4], shows many advantages over other conventional moments. L-moments of a probability distribution exist only if its mean is finite. Asymptotic approximations to sampling distributions are better for L-moments than for ordinary moments. Although moment ratios can be arbitrarily large, sample moment ratios have algebraic bounds. They are robust to outliers present in the data and give a better identification of the parent distribution for a given data sample [4].

The MLM has been extensively used by many researchers in a variety of fields such as engineering, meteorology, quality control, and hydrology (see for example [6-10]). So if our concern is about extreme events having undue influence, a robust estimation method developed to mitigate the influence of outliers on the final estimates should be used [5]. Elamir and Seheult [5] introduced an alternative robust version of L-moments called MTLM. The underlying notion of development of trimmed L-moments is the same as L-moments with some modification. MTLM was not developed with the intention to replace the existing robust method for outliers (MLM), but rather to complement them.

Practically, the true probability distribution of the data at a site is unknown. One purpose of FFA is to estimate the return period associated with a given flood magnitude. At-site FFA usually needs large data sets, but at most of the gauging sites data is of smaller recorded length compared to return periods of interest. But estimation of design floods usually requires some degree of extrapolation to achieve this objective. For the same reason, the selection of best fit distribution is of immense importance, as a wrong choice could lead to significant error and bias in designing flood estimates, especially at larger return periods. In the USA the log Pearson III (LPE3) has been suggested for extreme floods. Generalized logistic (GLO) and Pearson type III (PE3) are normally recommended in the UK and China, respectively. In Australia, the log-Pearson 3, generalized extreme value, and generalized Pareto distributions have been suggested as the three best-fit distributions [11]. However, there is no theoretical basis [12] to select a single probability distribution for all sites in a country (although goodness of fit tests can be used for distribution selection) [13]. The selection of only one candidate distribution should be avoided as there may be several distributions that pass statistical tests [11-14].

In Pakistan there is no official model that has been in practice for at-site FFA. Some efforts have been made to apply some models on such types of data, for example [15] studied two models on annual peak flows data and found that GEV is better than Gumbel distribution using flood data of six sites, while the successive study by [16] considered two distributions as gamma distribution and GLO for the same data and proposed that for some sites gamma distribution is a better choice and for some sites GLO is a better choice.

Our study is different in the sense that we are using three estimation methods: two robust estimation methods as MLM and MTLM, and one conventional method as MLE for AMSF data of 18 sites. The selection of best-fit distribution and best estimation method is decided on three goodness-of-fit tests, MADI, PPCC, and AD test, and L-moments ratio diagram. Initially we considered 10 distributions in our study such as generalized logistic (GLO), generalized extreme value (GEV), generalized Pareto (GPA), generalized normal (GNO), Pearson type 3 (PE3), logistic (LOG), normal (NORM), uniform (UNI), Gumbel (GUM), and exponential (EXP). On the basis of the above-mentioned goodness-of-fit tests, finally three distributions as GPA, GLO, and GEV are found to be most suitable distributions for different sites. Further, for initial screening of the data to check basic assumptions of hydrological data such as stationarity, homogeneity and independence, we have applied an extensive range of parametric and non-parametric tests such as the Mann-Whitney, Krushkal-Wallis, Ansari-Bradley, and lag 1 correlation tests, plus L-Jung box statistics.

In the current study we are going to select best distribution for individual sites separately on the basis of different goodness-of-fit tests using two robust estimation methods (MLM and MTLM) and one conventional method (MLE). Different goodness tests will support different probability distributions. All of the models cannot be evaluated by the same goodness-of-fit test [14-16].

After selection of best distribution for each individual site, the results obtained from FFA can be used in designing dams, culverts, bridges, and different kinds of flood-controlling devices.

\section{Data and Methodology}

\section{Data Description and Its Initial Screening}

The AMSF data of 18 sites of Pakistan located on five rivers - namely the Indus, Jhelum, Chenab, Ravi, and Sutlej - have been used in this study. These sites have been selected keeping in mind the standard criteria of hydrological 
Table 1. Basic information about all sites used in the study.

\begin{tabular}{|c|c|c|c|c|c|c|c|c|}
\hline $\begin{array}{l}\text { Name of } \\
\text { sites }\end{array}$ & River & $\begin{array}{l}\text { Latitude } \\
\text { (North) }\end{array}$ & $\begin{array}{l}\text { Longitude } \\
\text { (East) }\end{array}$ & $\begin{array}{l}\text { Sample size } \\
\text { (n) }\end{array}$ & Mean & $\begin{array}{l}\text { Standard } \\
\text { deviation }\end{array}$ & Skewness & $\begin{array}{l}\text { Coefficient } \\
\text { of variation }\end{array}$ \\
\hline Tarbela & \multirow{7}{*}{ Indus } & 33.99 & 72.61 & 54 & 386,960 & 87,786 & 2.6264 & 0.22686 \\
\hline Kalabagh & & 32.95 & 71.50 & 46 & 464,720 & 151,840 & 1.1861 & 0.32674 \\
\hline Chashma & & 32.43 & 71.38 & 43 & 475,330 & 149,640 & 1.2258 & 0.3148 \\
\hline Taunsa & & 30.50 & 70.80 & 56 & 452,790 & 140,790 & 1.80402 & 0.31094 \\
\hline Guddu & & 28.30 & 69.50 & 40 & 615,100 & 309,460 & 1.46604 & 0.50311 \\
\hline Sukkur & & 27.72 & 68.79 & 35 & 546,610 & 309,470 & 2.62907 & 0.56616 \\
\hline Kotri & & 25.22 & 68.22 & 113 & 436,750 & 258,590 & 4.1194 & 0.59208 \\
\hline Mangla & \multirow{2}{*}{ Jhelum } & 33.15 & 73.65 & 54 & 132,480 & 136,390 & 4.2402 & 1.0295 \\
\hline Rasul & & 32.68 & 73.50 & 44 & 134,420 & 161,220 & 3.5825 & 1.1994 \\
\hline Marala & \multirow{5}{*}{ Chenab } & 32.68 & 74.43 & 54 & 308,570 & 196,420 & 1.0973 & 0.63654 \\
\hline Khanki & & 32.40 & 73.92 & 54 & 361,160 & 231,460 & 1.185 & 0.64088 \\
\hline Qadirabad & & 32.33 & 73.73 & 44 & 356,550 & 247,770 & 1.0299 & 0.69492 \\
\hline Trimmu & & 31.14 & 72.15 & 46 & 261,380 & 261,380 & 1.0988 & 0.7454 \\
\hline Panjnad & & 29.33 & 71.00 & 44 & 260,130 & 193,660 & 1.97993 & 0.74447 \\
\hline Balloki & \multirow{2}{*}{ Ravi } & 31.22 & 73.86 & 54 & $91,272.0$ & $70,396.0$ & 1.77128 & 2.2267 \\
\hline Sidhani & & 30.58 & 72.07 & 54 & $70,600.0$ & $67,085.0$ & 1.834 & 0.95022 \\
\hline Sulemanki & \multirow{2}{*}{ Sutlej } & 30.38 & 73.86 & 39 & $70,255.0$ & $84,914.0$ & 2.2672 & 1.2087 \\
\hline Islam & & 29.82 & 72.55 & 40 & $49,089.0$ & $63,210.0$ & 2.3624 & 1.2876 \\
\hline
\end{tabular}

data such as area, record length, quality of data, urbanization, regulation, and climate variability and change. The data of these sites have been taken from the Water and Power Development Authority (WAPDA) and Federal Flood Commission (FFC). Usually, AMSF data at different sites have been recorded in the peak of monsoon season (from July to September). The information about different sites used in the study is given in Fig. 1 and Table 1.
The coefficient of skewness in Table 1 shows that all of the sites are positively skewed and away from normality.

Statistical analysis of hydrological data at different time scales generally meets in water resources, and planning studies are established on a set of vital assumptions, for example, stationarity, homogeneity, and independence. The violation of these assumptions will show erroneous results. Stationarity (the absence of a trend) implies that the

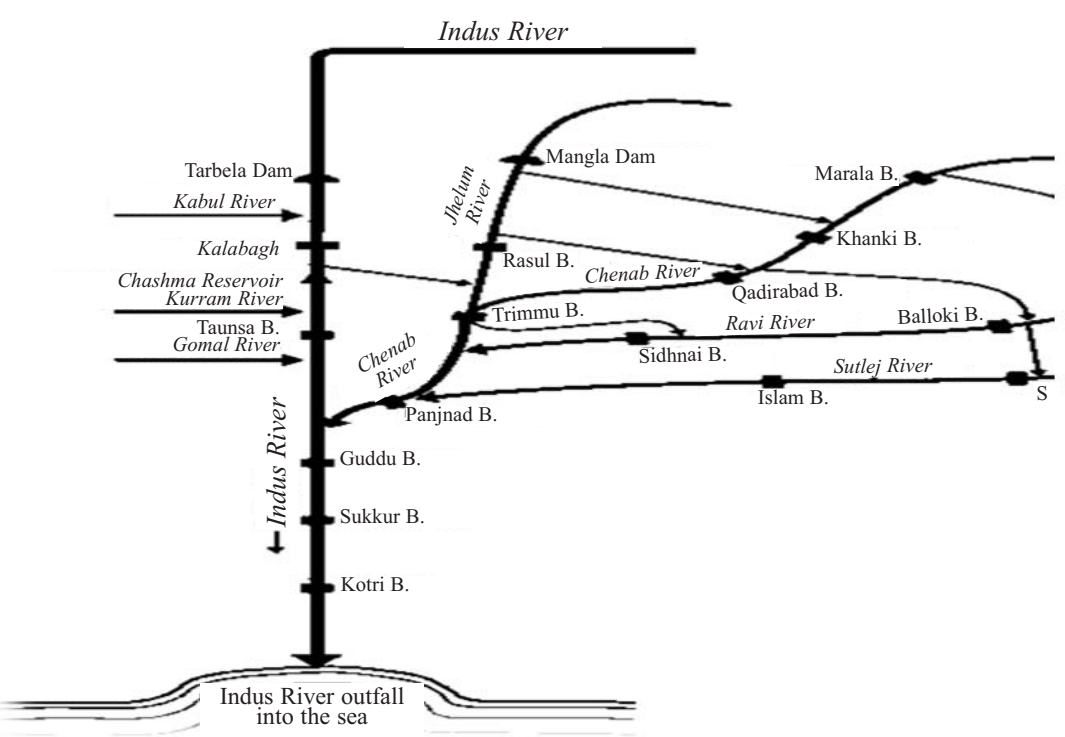

Fig. 1. Schematic diagrams of the 18 Sites of Pakistan used at-site FFA. 
future will be statistically not different from the past. Absence of trend may be checked through time series plots, Ljung box test statistics, and Spearman's rank-correlation coefficient. Homogeneity in a series implies that the data in the series belongs to one population and subsequently has a time-invariant mean.

In the current study we are considering homogeneity with respect to time. We have data on only one variable (i.e. the flow of water). We are not interested in space homogeneity, which is required for regional analysis. Sometimes homogeneity also is considered as consistency (stability with respect to mean and variance). Non-homogeneity in a series may occur due to variety of sources (e.g. changes in data collection method, climate change, changes in land used in the catchment, and changes in abstractions and river regulations). Assumption of homogeneity can be verified through the Mann-Whitney and Krushkal-Wallis tests, both of which are non-parametric. Mann-Whitney is a special case of the Krushkal-Wallis test when dealing with two samples instead of k samples to check stability or homogeneity with respect to location parameters. Verifying the homogeneity with respect to scale parameter is sometimes required for hydrological data in frequency analysis or system simulation. It is verified through the Ansari and Bradley test, a non-parametric version of F-test, in order to avoid the assumption of normality to check equality of variances. Usually the annual time series or seasonal total time series are independent. However, the assumption of independence is checked under special cases when data are from rivers, with a considerable carryover of groundwater flow from one year to the next and whose catchments include large lakes.

\section{Population L-Moments and Trimmed L-Moments}

L-moments are summary statistics for probability distributions and data samples. They are analogous to conventional moments. They also provide measures of location, dispersion, skewness, kurtosis, and other aspects of the shape of probability distributions or data samples, but in their computation we use linear combinations of the ordered data values.

Let $X_{1}, X_{2}, \ldots, X_{r}$ be the random sample of magnitude $r$, with cumulative distribution function $F(X)$ and quantile function $X(F)$. Let $X_{(1: r)} \leq X_{(2: r)} \leq \ldots \leq X_{(r: r)}$ be the order statistic of a random sample. For random variable $X$, the $r^{\text {th }}$ population L-moment as explained by [4] is:

$$
\begin{gathered}
\lambda_{r}=\frac{1}{r} \sum_{k=0}^{r-1}(-1)^{k}\left(\begin{array}{c}
r-1 \\
k
\end{array}\right) \mathrm{E}\left(X_{r-k: r}\right) \\
r=1,2, \ldots
\end{gathered}
$$

In L-moments L highlighted that $\lambda_{r}$ is a linear function of the expected order statistics. Normally we need the first four L-moments for $r=1,2,3,4$.

The L-moments ratio is defined as:

$$
\tau=\lambda_{2} / \lambda_{1}
$$

$$
\begin{gathered}
\tau_{3}=\lambda_{3} / \lambda_{2} \\
\tau_{4}=\lambda_{4} / \lambda_{2}
\end{gathered}
$$

...where $\tau$ is a measure of $\mathrm{L}$-coefficient of variation ( $\mathrm{L}-\mathrm{Cv}$ ), and $\tau_{3}$ and $\tau_{4}$ are L- Skewness and L-Kurtosis, respectively.

In Trimmed L-Moments the expectations of the order statistics of a conceptual sample (in the sense of population L-moments) are replaced by expectations of the order statistics of a larger conceptual sample, the size is increased equal to the total amount of trimming. Trimmed L-moments have a certain advantage over L-moments and conventional moments. Trimmed L-moments can exist even when a population mean does not exist. For example, Cauchy distribution. Sample trimmed L-moments are unbiased to the corresponding population quantities and more robust to outliers. In MTLM the " $E\left(X_{r-k: r}\right)$ " is substituted by " $E\left(X_{r+t_{1}-k: r+t_{1}+t_{2}}\right)$." Therefore, for every $r$ conceptual (Population) sample, we increased the sample size from $r$ to $\left(r+t_{1}+t_{2}\right)$ and work simply with the expectation of the $r$ order statistic $X_{t_{1+1: r+t_{1}+t_{2}}}, \ldots, X_{t_{1+r: r+t t_{1}+t_{2}}}$ by means of trimming $t_{1}$, the lowest value(s) and $t_{2}$ the largest value(s) from the random sample. There is an important concern about the optimal choice of trimming. According to [17], there are two approaches for this purpose. Both approaches are based on minimizing the criteria of variances, those trimming values will be chosen which provide less variance as compared to others.

We adopted the approach which based on minimizing the sum of absolute differences between theoretical quantile function and its trimmed L-moments representation. This approach deals with the probability model as a whole and will not be sensitive in choice of trimming for each parameter separately. Furthermore, this approach can also be used for optimal choice of trimming from the given data. In the current study the values of the sum of absolute differences of theoretical quantile function and its trimmed L-moment representation come with minimum value for all selected models in the study with trimming of (1.0). We have also empirical justification of using the trimming of (1.0) because the data of maximum stream flows are considered to be a random sample from some standard distribution such as GEV (see for example [18]).

In practice, the purpose of analyzing the data of AMSF is to predict the magnitude of floods for relatively larger return period events. Usually when analyzing the arid or semiarid regions, many very low or even zero AMSFs occur; [19-21] proposed a solution to this problem by censoring the data from the lower side. It might be that smaller sample values have only a nuisance value in the context of upper quantile estimation. In our study, we used unequal trimming value where just only one lowest value will be trimmed from our random sample $\left(t_{1}=1, t_{2}=0\right)$. The $r^{\text {th }}$ trimmed L-moment (TL-moment) is denoted by $\lambda_{r}^{\left(t_{1}, t_{2}\right)}$ and defined as: 


$$
\begin{gathered}
\lambda_{r}{ }^{\left(t_{1}, t_{2}\right)}=\frac{1}{r} \sum_{k=0}^{r-1}(-1)^{k}\left(\begin{array}{c}
r-1 \\
k
\end{array}\right) E\left(X_{r+t_{1}-k: r+t_{1}+t_{2}}\right) \\
r=1,2, \ldots
\end{gathered}
$$

The population TL-ratios for $(1,0)$ trimming are defined as:

$$
\begin{gathered}
\tau^{(1,0)}=\frac{\lambda_{2}{ }^{(1,0)}}{\lambda_{1}{ }^{(1,0)}} \\
\tau_{3}{ }^{(1,0)}=\frac{\lambda_{3}{ }^{(1,0)}}{\lambda_{2}{ }^{(1,0)}} \\
\tau_{4}{ }^{(1,0)}=\frac{\lambda_{4}{ }^{(1,0)}}{\lambda_{2}{ }^{(1,0)}}
\end{gathered}
$$

...where $\lambda_{1}^{(1,0)}$ is the measure of location, $\tau^{(1,0)}$ is the measure of TL-coefficient of variation (TL-Cv), and $\tau_{3}^{(1,0)}$ and $\tau_{4}^{(1,0)}$ are TL-Skewness and TL-Kurtosis, respectively.

\section{Estimation of L-Moments and TL-Moments}

In practice, L-moments need to be estimated after taking a random sample drawn from an anonymous distribution. Let $x_{1}, x_{2}, \ldots, x_{n}$ be the sample and $x_{1: n} \leq x_{2: n} \leq \ldots \leq x_{n: n}$ be the order statistics of the samples, then we can define the $r^{\text {th }}$ sample L-moments using [22] as:

$$
\begin{gathered}
l_{r}=\frac{1}{r} \sum_{i=1}^{n}\left[\sum_{j=0}^{r-1} \frac{(-1)^{j}\left(\begin{array}{c}
r-1 \\
j
\end{array}\right)\left(\begin{array}{c}
i-1 \\
r-1-j
\end{array}\right)\left(\begin{array}{c}
n-1 \\
j
\end{array}\right)}{\left(\begin{array}{c}
n \\
r
\end{array}\right)}\right] \mathrm{X}_{i: n} \\
r=1,2, \ldots
\end{gathered}
$$

The sample L-ratios are defined as:

$$
\begin{aligned}
& t=\frac{\ell_{2}}{\ell_{1}} \\
& t_{3}=\frac{\ell_{3}}{\ell_{2}} \\
& t_{4}=\frac{\ell_{4}}{\ell_{2}}
\end{aligned}
$$

...where $\ell_{1}$ is the measure of location, $t$ is measure of L-coefficient of variation (L-Cv), and $t_{3}$ and $t_{4}$ are the sample L-Skewness and L-Kurtosis, respectively. In summary, these statistics measure $\ell_{1}, \ell_{2}, t, t_{3}$, and $t_{4}$, and are very useful for sample data. These measures are used to classify the distribution from which the sample is drawn. Furthermore, these measures are used in the estimation of parameters when distribution is fitted to a sample by equating the sample L-moments and population L-moments.

The $r^{\text {th }}$ sample TL-moments are defined as:

$l_{r}^{\left(t_{1}, t_{2}\right)}=\frac{1}{r} \sum_{j=t_{1+1}}^{n-t_{2}}\left[\sum_{k=0}^{r-1} \frac{(-1)^{k}\left(\begin{array}{c}r-1 \\ k\end{array}\right)\left(\begin{array}{c}j-1 \\ r+t_{1}-k-1\end{array}\right)\left(\begin{array}{c}n-j \\ t_{2}+k\end{array}\right)}{\left(\begin{array}{c}n \\ r+t_{1}+t_{2}\end{array}\right)}\right] x_{j: n}$
As in this study we use trimming of $\left(t_{1}=1, t_{2}=0\right)$. In this case we can write the above as given below.

$$
\begin{aligned}
& \mathrm{t}_{3}^{(1,0)}=\frac{\ell_{3}^{(1,0)}}{\ell_{2}^{(1,0)}} \\
& \mathrm{t}_{4}^{(1,0)}=\frac{\ell_{4}^{(1,0)}}{\ell_{2}^{(1,0)}}
\end{aligned}
$$

The TL-skewness and TL-kurtosis are dimensionless computed shapes of a data set. Parameters estimation of the different distribution using MLM and MTLM has been given in [3], and [23-25], respectively.

\section{Goodness of Fit Tests}

The goodness-of-fit tests such as MADI, PPCC, and AD using MLM and MTLM are applied to find the most suitable distribution for a specific site. MADI and PPCC have been used in different studies (for example see [23], $[9,25-27]$, and many others). Similarly, the AD test is frequently used in many studies such as [12] and [28-31].

\section{Mean Absolute Deviation Index (MADI)}

The goal of this method is to check whether a given distribution fits the data closely by selecting from a number of candidate distributions. We choose that one which gives the best fits to the data. The MADI is calculated by:

$$
M A D I=\frac{1}{N} \sum_{i=1}^{N}\left|\frac{x_{i}-y_{i}}{x_{i}}\right|
$$

...where $x_{i}$ are the observed flows, $y_{i}$ the predicted flows, and $N$ is the number of observations at a site. Here we use the Hosking plotting position formula to calculate predicted flows using $F$, non-exceedance probability.

$$
F=\frac{(j-0.35)}{n}, \quad \mathrm{j}=1,2, \ldots \mathrm{n}
$$

$\ldots$ where $j$ is the observation in ascending order and $n$ is sample size. The mean absolute deviation index (MADI) of smaller value obtained for given distribution shows that the distribution is more closely fitted to the actual data.

\section{Probability Plots Correlation Coefficient (PPCC)}

Basically it is the relationship between current observations and corresponding predicted plotting position. Correlation between the current and predicted flows are given by:

$$
r=\frac{\sum_{i=1}^{n}\left[\left(x_{i}-\bar{x}\right)\left(y_{i}-\bar{y}\right)\right]}{\sqrt{\sum_{i=1}^{n}\left(x_{i}-\bar{x}\right)^{2} \sum_{i=1}^{n}\left(y_{i}-\bar{y}\right)^{2}}}
$$


The range of correlation $r$ is -1 to +1 . When a value of correlation of fitted distribution is closer to 1 or -1 it suggests that the current data have been drawn from the fitted distribution and when a value of correlation of fitted distribution is closer to 0 it suggests that the current data is not drawn from the fitted distribution.

\section{Anderson Darling (AD) Test}

The AD test is used to check whether the given sample of data is drawn from a given probability distribution. It is a general test to compare observed distribution function to an expected distribution function. The $\mathrm{AD}$ test gives extra weight to the tail than the Kolmogorov-Simonov test, which makes it more powerful. The $\mathrm{AD}$ test statistics $A^{2}$ as defined as:

$A^{2}=-n-\frac{1}{n} \sum_{i=1}^{n}(2 i-1)\left[\operatorname{In} F\left(X_{i}\right)+\operatorname{In}\left(1-F\left(X_{n-i+1}\right)\right)\right]$

...where $n$ is the sample size and $F$ is the distribution function. The null hypothesis at the chosen level of significance will be rejected if the calculated value of the above statistic is greater than the critical value obtained from a table. In general, critical values of the Anderson-Darling test statistic depend on the specific distribution being used. However, tables of critical values for many distributions (except several the most widely used ones) are not easy to find. We used the AD test as implemented in Easy Fit, which uses the same critical values for all distributions. After calculation of this statistic values for all of the operating models, one selects the model with the minimum $\mathrm{AD}$ value.

\section{L-Moment and TL-Moment Ratio Diagrams}

The simplest method to determine the best distribution to fit the actual data is by using L-moment and TL-moment ratio diagrams, which are based on relationships between the L-moment and TL-moment ratios, respectively. The Lmoment and TL-moment ratio diagrams provide a graphical indication of which distribution can be expected to give a better fit to the sample data or samples. Therefore, this allows better discrimination between the distributions.

\section{Quantiles of Best Fit Distribution}

One of the objectives of FFA is to get handy estimates of the quantiles for return period of scientific significance. After selection of best fit distribution and estimation of its parameters, we need to find the Quantiles'estimates corresponding to different return periods $(T)$. Maximum stream flows do not occur with any fixed pattern in time or magnitude. Large floods naturally have large return periods with less probability and vice versa. The relationship between return periods and occurrence of an extreme event (e.g. amount of flow greater than or equal to some threshold value in a dam) may be established through the notion of geometric random variable as: $T=1 / p$, where $\mathrm{p}$ is the probability of occurrence of $T$ year return period event (i.e. $X \geq x_{t}$ ).

Suppose we have a five-year return period event that yields a probability of occurrence equal to 0.2 and the corresponding quantile value based on this probability and best-fit distribution (whatever you select) is 500 cusec (say). We can say that a five-year return period event will occur ( $\geq 500$ cusec on average once in five years) with probability 0.2 . Sometimes we are interested in finding out the probability of a $T$-year return period event to occur at least once in the next $N$ years. The answer to this equation can be achieved using the relationship given by: $1-(1-1 / T)^{N}$. In the case of a five-years return period event (as discussed above), the probability of this five-year return period event occurring at least once in the next five years is 0.672 .

\section{Results and Discussion}

All of the tests mentioned in the previous section show that AMSF is stationary, homogeneous, and independent, and is suitable for further analysis (Fig. 2).

The L-moments ratio diagram shows visual inspection about the best distribution for different sites. On the basis of this ratio diagram and three goodness-of-fit tests, it is found that out of 10 distributions, only three are suitable for AMSF data of different sites. The visual inspection is clear in the following ratio diagram (Fig. 3) and results of other goodness-of-fit tests are shown in Table 2.

From Table 2 it is clear that using MADI and GLO is the best fit distribution for five sites, while GEV and GPA for six and seven sites, respectively. Using AD, numbers of sites for which GLO, GEV, and GPA are best fit distributions are seven, one, and 10, respectively. Similarly, using PPCC numbers of sites for which GLO, GEV, and GPA are best fit distributions are five, four, and nine. The results of the ratio diagram are very close to the $\mathrm{AD}$ test. Among three estimation methods, MLM is found to give best results for most of the sites.

For four sites, trimmed L-moments is also found to give best results. MLE is a suitable estimation method only for the Kotri site. One of the reasons behind this may be of sam-

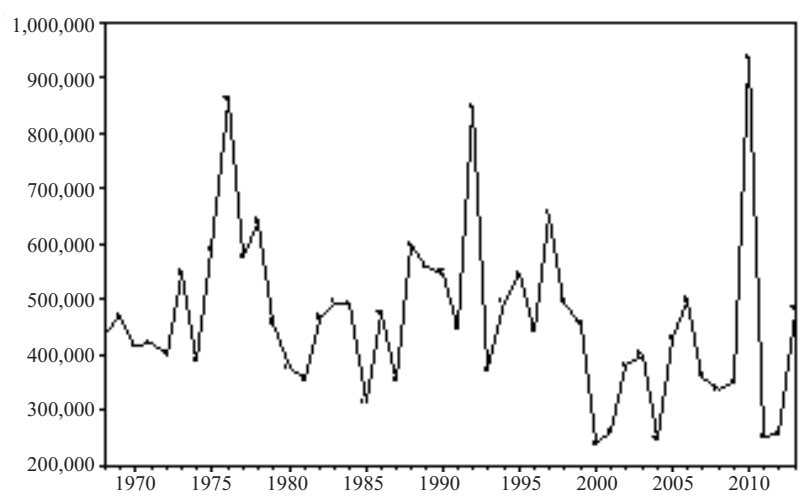

Fig. 2. Time series plots of Kalabagh Site. 
Table 2. Results of different goodness-of-fit tests and estimation methods.

\begin{tabular}{|c|c|c|c|c|c|c|}
\hline Sites name & MADI & PPCC & $\mathrm{AD}$ & Ratio diagram & Best distribution & Best method of estimation \\
\hline Tarbela & GLO & GLO & GLO & GLO & GLO & MLM \\
\hline Kalabagh & GEV & GLO & GLO & GLO & GLO & MLM \\
\hline Chashma & GEV & GLO & GLO & GLO & GLO & MLM \\
\hline Taunsa & GLO & GLO & GLO & GLO & GLO & MLM \\
\hline Guddu & GPA & GLO & GLO & GLO & GLO & MLM \\
\hline Sukkur & GPA & GEV & GPA & GPA & GPA & MLM \\
\hline Kotri & GEV & GEV & GEV & GLO & GEV & MLE \\
\hline Mangla & GLO & GEV & GLO & GLO & GLO & MLM \\
\hline Rasul & GLO & GLO & GEV & GEV & GEV & MLM \\
\hline Marala & GEV & GPA & GPA & GPA & GPA & MTLM \\
\hline Khanki & GPA & GPA & GPA & GPA & GPA & MTLM \\
\hline Qadirabad & GPA & GPA & GPA & GPA & GPA & MTLM \\
\hline Trimmu & GEV & GPA & GPA & GPA & GPA & MTLM \\
\hline Panjnad & GPA & GPA & GPA & GPA & GPA & MLM \\
\hline Balloki & GEV & GPA & GLO & GPA & GPA & MLM \\
\hline Sidhani & GPA & GEV & GPA & GPA & GPA & MLM \\
\hline Sulemanki & GPA & GPA & GPA & GPA & GPA & MLM \\
\hline Islam & GPA & GPA & GPA & GPA & GPA & MLM \\
\hline
\end{tabular}

ple size greater than 100 observations. Most of the sites follow GPA distribution followed by GLO and GEV. None of these sites follows GNO, PE3, LOG, NORM, UNI, GUM, and EXP, indicating that these distributions have a poor fit for AMSF of any site in this study. This can also be viewed from the L-moments ratio diagram. Minimum numbers of 35 observations are being considered in each site in order to avoid any misleading results in every goodness of fit test due to small sample size. One of the objectives at-site FFA is to estimate a different return period associated with a given flood magnitude (quantiles of best fit distribution/maximum annual discharge values), which are useful for hydrologists in the planning and design of hydraulic structures. To gain this purpose we constructed Table 3. Quantile estimates are calculated on the basis of best-fit distributions for each site individually and it is found that these quantiles are in close agreement to observed values of AMSF, which can be indicated through extreme value plots.

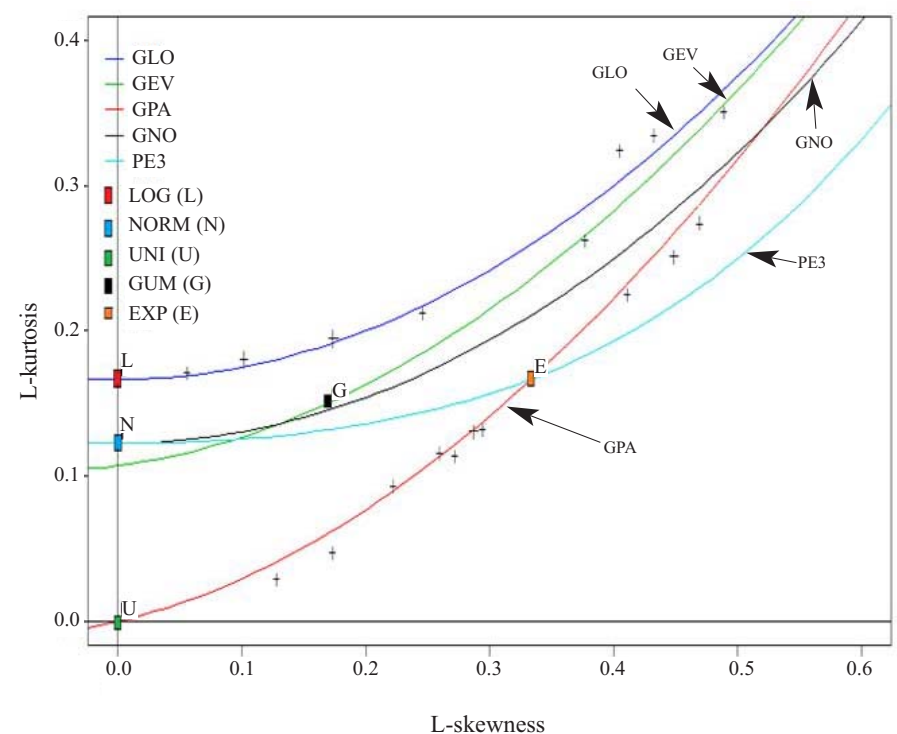

Fig. 3. L-moments ratio diagram for 18 sites of Pakistan. 
Table 3. Quantile estimates for each site for different return periods using best-fit distribution.

\begin{tabular}{|c|c|c|c|c|c|c|c|c|c|}
\hline Sites & & 0.500 & 0.800 & 0.900 & 0.950 & 0.980 & 0.990 & 0.998 & 0.999 \\
\hline name & distribution & 2 & 5 & 10 & 20 & 50 & 100 & 500 & 1,000 \\
\hline Tarbela & \multirow{4}{*}{ GLO } & $370,093.687$ & $434,196.502$ & $483,173.747$ & $537,822.565$ & $623,241.434$ & $700,849.147$ & $939,573.703$ & $1,074,986.194$ \\
\hline Kalabagh & & $441,788.301$ & $563,034.493$ & $648,762.569$ & $739,211.366$ & $872,163.744$ & $986,046.947$ & $1,307,419.711$ & $1,475,607.498$ \\
\hline Chashma & & $460,582.922$ & $577,927.366$ & $655,590.199$ & $733,732.327$ & $842,782.048$ & $931,630.693$ & $1,164,862.478$ & $1,278,790.008$ \\
\hline Taunsa & & $445,711.906$ & $556,101.160$ & $624,760.857$ & $690,846.241$ & $778,710.236$ & $847,018.979$ & $1,014,713.265$ & $1,091,470.461$ \\
\hline Guddu & \multirow{2}{*}{ GPA } & $566,474.791$ & $910,791.161$ & $1,077,886.586$ & $1,192,325.122$ & $1,290,242.186$ & $1,337,760.964$ & $1,398,150.880$ & $1,411,664.322$ \\
\hline Sukkur & & $483,104.035$ & $828,009.585$ & $1,015,117.387$ & $1,155,933.267$ & $1,290,098.660$ & $1,362,882.040$ & $1,469,847.471$ & $1,498,159.601$ \\
\hline Kotri & \multirow{3}{*}{ GLO } & $295,709.114$ & $522,116.107$ & $727,002.354$ & $985,651.369$ & $1,448,912.443$ & $1,928,001.511$ & $3,716,497.052$ & $4,924,553.028$ \\
\hline Mangla & & $96,348.508$ & $169,097.689$ & $238,056.774$ & $328,132.863$ & $495,683.123$ & $675,253.276$ & $1,383,050.346$ & $1,884,418.383$ \\
\hline Rasul & & $86,965.836$ & $172,632.289$ & $257,317.727$ & $371,419.800$ & $591,093.095$ & $834,275.297$ & $1,841,644.643$ & $2,586,517.796$ \\
\hline Marala & \multirow{5}{*}{ GPA } & $249,137.657$ & $448,900.141$ & $589,575.977$ & $721,853.822$ & $884,674.980$ & $999,336.163$ & $1,239,863.617$ & $1,333,320.937$ \\
\hline Khanki & & $291,775.676$ & $525,720.579$ & $690,150.990$ & $844,509.716$ & $1,034,146.892$ & $1,167,435.194$ & $1,446,280.386$ & $1,554,324.703$ \\
\hline Qadirabad & & $285,960.094$ & $544,535.730$ & $717,548.006$ & $873,249.863$ & $1,055,429.295$ & $1,177,325.072$ & $1,415,379.292$ & $1,501,260.946$ \\
\hline Trimmu & & $202,697.197$ & $400,553.823$ & $539,619.245$ & $670,166.636$ & $830,550.433$ & $943,277.718$ & $1,179,108.327$ & $1,270,485.757$ \\
\hline Panjnad & & $190,832.068$ & $408,309.117$ & $554,700.398$ & $687,125.401$ & $842,994.256$ & $947,914.942$ & $1,154,539.198$ & $1,229,737.327$ \\
\hline Balloki & GEV & $70,622.589$ & $122,090.639$ & $167,123.272$ & $220,922.505$ & $310,165.709$ & $395,360.808$ & $675,642.860$ & $844,398.439$ \\
\hline Sidhani & \multirow{3}{*}{ GPA } & $47,194.296$ & $103,216.021$ & $151,597.855$ & $205,846.856$ & $287,785.277$ & $358,549.451$ & $557,739.716$ & $661,240.718$ \\
\hline Sulemanki & & $39,793.243$ & $104,949.643$ & $164,935.000$ & $236,032.038$ & $350,619.247$ & $456,112.410$ & $782,665.744$ & $968,191.144$ \\
\hline Islam & & $54,008.070$ & $107,152.122$ & $155,782.439$ & $213,117.796$ & $304,956.073$ & $388,994.161$ & $646,781.230$ & $792,007.513$ \\
\hline
\end{tabular}

\section{Conclusions}

Due to climate change, the forecasting future flows is burdened with uncertainty. In vulnerable regions even large data sets cannot solve the problem. However, this study investigates the selection of best-fit probability distribution and estimation method for at-site FFA in Pakistan using the AMSF of 18 sites. Three goodness-of-fit methods such as mean absolute deviation index (MADI), the Anderson Darling (AD) test, and probability plot correlation coefficient (PPCC) are adopted for this purpose. L-moments ratio diagram is also used for visual inspection of goodness-offit criteria. Out of 10 probability distributions, GPA, GLO, and GEV are considered the top three best fit distributions for annual maximum stream flow data of different sites in Pakistan. Most sites follow GPA (56\%), followed by GLO (33\%) and GEV (11\%). Among three estimation methods, the MLM is found to be the more suitable method at $72 \%$ of the sites, MTLM at $22 \%$ of the sites, and MLE at only $5 \%$ of the sites. Flows based on the fitted distribution are also in close agreement to the observed flows.

\section{Acknowledgements}

We are very thankful to Water and Power Development Authority, Pakistan and National Flood Commission,
Pakistan in provision of required data. Further, we also very thankful to Higher Education Commission for providing us financial assistance under project No. 20-3954R\&D/HEC/ $14 / 305$.

\section{References}

1. SIEGENTHALER U., STOCKER T. F., MONNIN E., LÜTHI D., SCHWANDER J., STAUFFER, B. RAYNAUD D., BARNOLA J.M., JOUZEL J-M., FISCHER H., DELMOTTE V.M., JOUZEL J. Stable Carbon Cycle-Climate Relationship during the Late Pleistocene. Science. 310, 1313, 2005.

2. NOTO L. V., LA LOGGIA G. Use of L-Moments Approach for Regional Flood Frequency Analysis in Sicily, Italy. Water Resour. Manag. 23, 2207, 2009.

3. HOSKING J. R. M., WALLIS J. R. Regional frequency analysis: an approach based on L-moments. Cambridge University Press, United Kingdom. 1997.

4. HOSKING J.R.M. L-Moments: Analysis and Estimation of Distributions using Linear Combinations of Order Statistics. Journal of Royal Statistical Society B. 52, 105, 1990.

5. ELAMIR E., SEHEULT A.H. Trimmed L-Moments. Comput. Stat. Data An. 43, 299, 2003.

6. KUMAR R., GOEL N. K., CHATTERJEE C., NAYAK P. C. Regional Flood Frequency Analysis using Soft Computing Techniques. Water Resour. Manag. 29, 1965, 2015. 
7. PARIDA B.P., MOALAFHI D.B. Regional rainfall frequency analysis for Bostwana using L-Moments and radial basis function network. Phys. Chem. Earth Pt A/B/C. 33, 614, 2008.

8. SAF B. Regional Flood Frequency Analysis Using LMoments for the West Mediterranean Region of Turkey. Water Resour. Manag. 23, 531, 2009.

9. IZINYON O. C., EHIOROBO J. O. L-moments approach for flood frequency analysis of river Okhuwan in BeninOwena River basin in Nigeria. Nigerian Journal of Technology. 33, 10, 2014.

10. FISCHER S., SCHUMANN A. Robust flood statistics-comparison of peak over threshold approaches based on monthly maxima and TL-moments. Hydrolog. Sci. J. 2015. DOI: 10.1080/02626667.2015.1054391,

11. RAHMAN A. S., RAHMAN A., ZAMAN M. A., HADDAD K., AHSAN A., IMTEAZ M. A study on selection of probability distributions for at-site flood frequency analysis in Australia. Nat. Hazards. 69, 1803, 2013.

12. CALENDA G., MANCINI C. P., VOLPI E. Selection of the probabilistic model of extreme floods: The case of the River Tiber in Rome. J. Hydrol. 371, 1, 2009.

13. DI BALDASSARRE G., LAIO F., MONTANARI A Design flood estimation using model selection criteria, Phys. Chem. Earth Pt. A/B/C. 34, 606, 2009.

14. KIDSON R., RICHARDS K. S. Flood frequency analysis: assumptions and alternatives. Prog. Phys. Geog. 29, 392, 2005.

15. FAQIR M., AFREEN S. Modeling annual maximum peak flows at various dams and barrages in Pakistan. Journal of Hydrology and Hydromechanics/Vodohospodarsky Casopis, 55, 43, 2007.

16. AFREEN S., FAQIR M. Flood frequency analysis of various dams and barrages in Pakistan. Irrigation and Drainage. 61, 116, 2012.

17. ELAMIR E. A. H. Optimal choices for trimming in trimmed L-moment method. Applied Mathematical Sciences. 58, 2881, 2010.

18. SHABRI A. B., DAUD Z. M., ARIFF N. M. Regional analysis of annual maximum rainfall using TL-moments method. Theor. Appl. Climatol. 104, 561, 2011.

19. BHATTARA K. P. Flood frequency analysis of Irish river flow data using variants of L-Moment. In National Hydrology Seminar. 2005.

20. CUNNANE C. Review of statistical models for flood frequency estimation. In Hydrologic frequency modeling, Springer, Netherlands, 1987.

21. WANG Q. J. Estimation of the GEV distribution from censored samples by method of partial probability weighted moments. J. Hydrol. 120, 103, 1990.

22. ASQUITH W. H. L-moments and TL-moments of the generalized lambda distribution. Comput. Stat. Data An. 51, 4484, 2007.

23. AHMAD U. N., SHABRI A., ZAKARIA Z. A. Trimmed Lmoments $(1,0)$ for the generalized Pareto distribution. Hydrolog. Sci. J. 56, (6), 1053, 2011.

24. AHMAD U. N., SHABRI A., ZAKARIA Z. A. TL-moments and L-moments estimation of the generalized logistic distribution. Journal of Mathematics Research. 3, 97, 2011.

25. AHMAD U. N., SHABRI A., ZAKARIA Z. A. Flood frequency analysis of annual maximum stream flows using Lmoments and TL-moments approach. Applied Mathematical Sciences. 5, 243, 2011.

26. SHABRI A., ARIFF N. Frequency analysis of maximum daily rainfalls via l-moment approach. Sains Malaysiana. 38, 149, 2009.

27. DEKA S., BORAH M., KAKATY S. C. Distributions of Annual Maximum Rainfall Series of North-East India. European Water. 27, 3, 2009.

28. PALYNCHUK B., GUO Y. Threshold analysis of rainstorm depth and duration statistics at Toronto, Canada. J. Hydrol. 348, 535, 2008.

29. HADDAD K., RAHMAN A. Selection of the best fit flood frequency distribution and parameter estimation procedure: a case study for Tasmania in Australia. Stoch. Env. Res. Risk A. 25, 415, 2011.

30. LAIO F., DI BALDASSARRE G., MONTANARI A Model selection techniques for the frequency analysis of hydrological extremes. Water Resour. Res. 45, 2009. doi:10.1029/2007WR006666

31. BESKOW S., CALDEIRA T. L., DE MELLO C. R., FARIA L. C., GUEDES H. A. S. Multiparameter probability distributions for heavy rainfall modeling in extreme southern Brazil. Journal of Hydrology: Regional Studies, 4, 123, 2015. 
